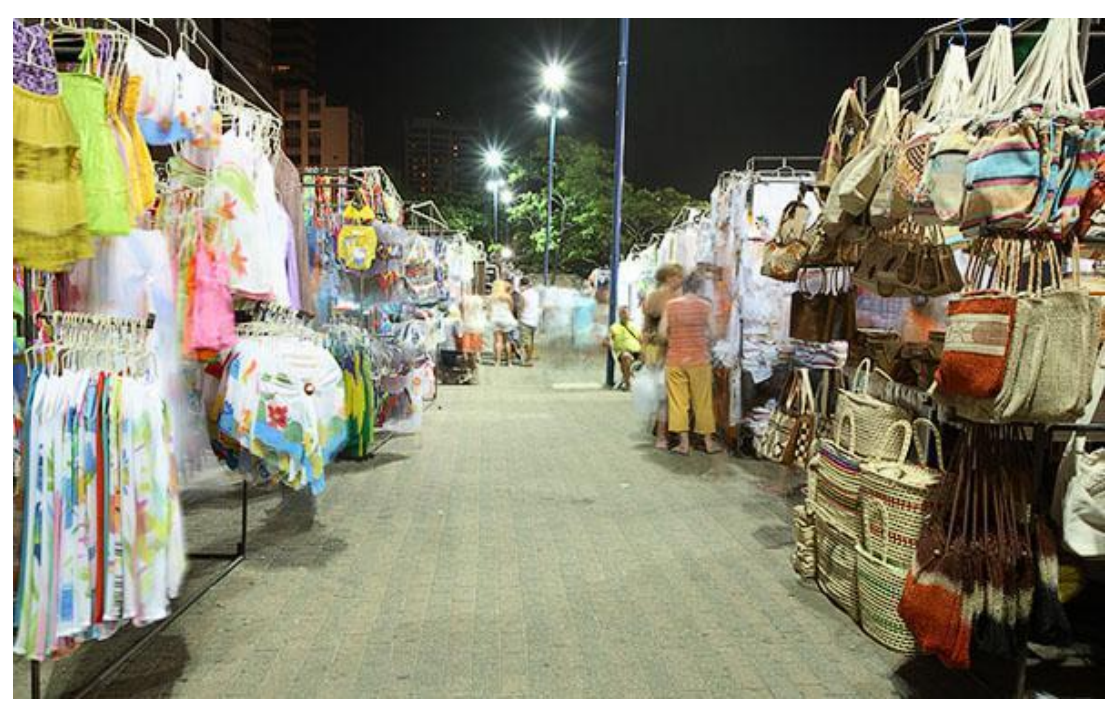

\title{
"Pra tá aqui tem que montar, desmontar e carregar". Mobilidade, território e cotidiano do trabalho na feira de artesanato da Avenida Beira-mar, Fortaleza (CE)*
}

"To be here one has to assemble, to disassemble and to carry": Mobility, territory and labor quotidian in the craft fair, on Beira-mar Avenue, Fortaleza (CE)

Luiz Antonio Araújo Gonçalves**

\section{Resumo}

Este trabalho teve como objetivo refletir sobre a relação do trabalho informal e a cidade por meio da territorialização e mobilidade do comércio ambulante de artesanato na avenida BeiraMar de Fortaleza (CE). Buscou-se tratar do cotidiano do trabalho na feira de artesanato, denominada "feirinha da Beira-Mar", a partir da dimensão do território e da mobilidade dos trabalhadores e trabalhadoras na constituição da feira que é montada e desmontada, todos os dias, no calçadão da orla.

Palavras-chave: Comércio Ambulante, Artesanato, Mobilidade, Território, Territorialidade.

\section{Abstract}

This work aimed to reflect about the relation of the informal work and the city by means of the territorialization and mobility of the craftwork street trading on Beira-Mar Avenue, Fortaleza (CE). It tried to deal with labor quotidian in the craft fair, named "feirinha da Beira-Mar", from the territorial dimension and mobility of workers in the constitution of the fair which is assembled and disassembled every day, on the waterfront's boardwalk.

Keywords: Street trading, Craftwork, Mobility, Territory, Territoriality.

\footnotetext{
* Este artigo é uma versão adaptada dos tópicos: Cotidiano e trabalho precário na Beira-Mar de Fortaleza e A organização do trabalho no interior da feira e a formação dos subcircuitos do trabalho precário, de minha dissertação intitulada Traçando mobilidades e tecendo territorialidades: o comércio de artesanato na Beira-Mar de Fortaleza (CE) - defendida junto ao Mestrado Acadêmico em Geografia (MAG), da Universidade Estadual do Ceará (UECE), em julho de 2009. Esse trabalho de dissertação contou, ainda, com o apoio (projeto contemplado) do Programa de Apoio à Elaboração de Teses e Dissertações, do Escritório Técnico de Estudos Econômicos do Nordeste (ETENE), do Banco do Nordeste do Brasil (BNB), por meio do Fundo de Desenvolvimento Científico e Tecnológico (FUNDECI).

${ }^{* *}$ Doutorando em Geografia (PropGEO/UECE). Professor Substituto do Curso de Geografia Bach./Licenc. Membro do Laboratório de Estudos Urbanos e Geografia Cultural (LEURC), da Universidade Estadual do Ceará (UECE). Endereço postal: Universidade Estadual do Ceará, Centro de Ciências e Tecnologia, Bloco do Programa de Pós-Graduação em Geografia, Lab. de Estudos Urbanos e Geografia Cultural. Av. Paranjana, 1700, CEP: 60.740-903, Campus do Itaperi, Serrinha - Fortaleza/CE. Endereço eletrônico: geoluiz@ hotmail.com
} 


\section{Introdução}

Os espaços públicos das grandes cidades nordestinas, mais especificamente as que se encontram nas faixas litorâneas, têm atraído grande número de trabalhadores que buscam oportunidades de trabalho e renda em atividades tradicionais, como o artesanato. Nas duas últimas décadas, o desenvolvimento do turismo contribuiu, sem dúvida, para a expansão das vendas de produtos artesanais.

Este artigo trata do cotidiano do trabalho na feira de artesanato, denominada "feirinha da Beira-Mar", situada na orla marítima/turística da cidade de Fortaleza (CE). Buscou-se, assim, dar conta de tal proposição a partir da dimensão do território e da mobilidade dos trabalhadores e trabalhadoras na constituição da feira que é montada e desmontada, todos os dias, no calçadão da orla.

A relação estabelecida entre os feirantes, também chamados permissionários, foi um aspecto relevante, pois revelou a organização do trabalho no interior da feira e a formação de subcircuitos do trabalho, a exemplo do serviço de montagem e desmontagem das barracas. Esse trabalho diário é realizado por pessoas contratadas, que fazem, igualmente, a instalação de baterias, utilizadas na iluminação das barracas, além do transporte das mercadorias do depósito, situado nas proximidades da avenida BeiraMar, até o calçadão, local de instalação das barracas.

Antes, porém, é interessante situar o leitor no contexto do trabalho informal na orla marítima de Fortaleza. Nas últimas décadas, a avenida Beira-Mar tornou-se um espaço marcado pela valorização da paisagem litorânea e pelo acirramento da busca por um lugar com vista para o mar. A proximidade do principal corredor da hotelaria do estado do Ceará revelou-se um fator determinante na fixação da feira, atraindo, inclusive, comerciantes de outras centrais artesanais, como o Mercado Central e o Centro de Turismo, ambos localizados no centro antigo da cidade. A localização estratégica da feira influenciou, também, a concentração de vendedores ambulantes no calçadão da Beira-Mar.

É no calçadão, entretanto, onde se estabelecem novas apropriações e se misturam diferentes grupos sociais, compreendendo: turistas, residentes da área, moradores de bairros próximos e distantes, situados na periferia da cidade. Enquanto muitos vão ao calçadão para fazer exercícios, passeios, caminhadas, outros vão a trabalho, ou seja, em busca de renda que lhes permita o sustento. Esses grupos sociais, 
que sobrevivem do trabalho desenvolvido no calçadão, constroem diferentes territorialidades em meio a essa diversidade de apropriações e usos.

A feira de artesanato da Beira-Mar se estabeleceu como um dos pontos de venda de artesanato mais movimentados de Fortaleza, concentrando grande variedade de produtos regionais. Os turistas que se hospedam nos hotéis da orla são atraídos pela proximidade das barracas montadas do outro lado da avenida. A feira tem início no final da tarde, estendendo-se pelo período da noite, quando parte dos turistas retorna dos passeios às praias do litoral cearense, e outros locais de comércio de artesanato já se encontram fechados.

O território da feira é demarcado pelo grande número de barracas, onde são vendidos diversos produtos artesanais, principalmente peças bordadas a mão ou a máquina, trabalhos em filé ${ }^{1}$, crochê, rendas de bilro, bolsas, sandálias e outros artigos de couro, garrafas de areia colorida, toalhas de mesa, colchas de cama bordadas, brinquedos artesanais, bonecas de pano, redes de dormir, tapetes, chapéus e bolsas de palha de carnaúba e/ou de buriti, entalhes de madeira, esculturas (madeira, aço, prata, bronze), doces caseiros, rapadura, castanha de caju, licores, aguardente, cajuína, molhos e temperos, bijuterias artesanais, adornos, dentre outros produtos oferecidos ao turista.

Além destes, são vendidos outros produtos tidos como não artesanais, mas que, da mesma forma, são apreciados e adquiridos pelos turistas, como confecção, camisaria, moda praia, bijuteria, camisas de clubes de futebol, óculos de praia, calçados, sandálias industrializadas (havaianas), bonés, moda íntima feminina, biquínis e brinquedos industrializados.

Compõem, ainda, a relação de produtos comercializados no calçadão comidas da cultura regional, destacando-se: milho verde cozido, rolete de cana, mungunzá, pamonha, tapioca, camarão e acarajé, vendidos em pontos fixos ou móveis espalhados pelo calçadão. São comercializadas, também, bebidas, como a tradicional água de coco, além de água mineral, refrigerantes, sucos e energéticos.

Em síntese, essa porção da orla se destaca pela dinâmica própria que marca o cotidiano do trabalho informal no calçadão, sobretudo na feira de artesanato da beiramar, como poderemos verificar mais adiante.

\footnotetext{
${ }^{1}$ Compreende a técnica artesanal de tecer a mão, com agulha, uma trama de fios de algodão feita sobre uma grade de madeira, formando peças que, em geral, são utilizadas para fins decorativos.
} 


\section{Mobilidade, território e cotidiano do trabalho na feirinha da beira-mar}

Para a maioria dos feirantes o trabalho na feira é diário e sem folga, principalmente aos sábados e domingos, quando o volume das vendas é maior, porém o dia de folga que reservam para si é revestido de certa angústia e culpa pelo dia não trabalhado, pela mercadoria não vendida que ficou parada na barraca. Conforme o relato de um feirante: “[...] torna-se um ciclo vicioso, se não vir (sic), acha que poderia ser melhor as vendas".

O local de trabalho, todavia, parece diluir o cansaço e a fadiga da rotina de todos os dias na feira, ajudada, outrossim, pelo ambiente litorâneo, o que faz com que muitos passem a ver aquela atividade de modo menos desgastante. Nesse sentido, o tempo de trabalho e o tempo de repouso também se misturam para muitos feirantes, à medida que se inserem no cotidiano da feira. Quando perguntados sobre o que lhes agradava no trabalho da feira, muitos feirantes apontaram como vantagem o ambiente e a paisagem, ou seja, o calçadão da Beira-Mar.

Para aquele trabalhador que passa o período diurno confeccionando suas peças, estar à noite na feira vendendo seus produtos constitui uma quebra de rotina. Em seu entendimento, esse é um momento de descanso. De outro modo, pode-se afirmar que, nesse caso, há um acúmulo de trabalho, uma vez que o feirante produz e comercializa consecutivamente.

O território demarcado no calçadão se torna, igualmente, um espaço de sociabilidade e de contato com outros costumes e sotaques. O contato com pessoas de vários estados brasileiros e de outros países, além do fato de sair de casa, ou seja, alterar a "rotina" diária, revela-se um aspecto positivo para muitos que trabalham na feira. A Beira-Mar torna-se, contraditoriamente, a quebra da rotina que se repete todos os dias na vida de cada feirante com a montagem/desmontagem das barracas no calçadão. Para outros feirantes a feira torna-se um fardo, um "serviço pesado", que tem início já no trajeto casa/Beira-Mar, principalmente para aqueles que não possuem carro próprio e têm que se deslocar de ônibus, muitas vezes, trocando de veículo para atingir o destino final. Ao chegar à Beira-Mar, dedicam-se, inicialmente, à montagem das mercadorias na barraca e, em alguns casos, a condução do carrinho onde são transportadas as mercadorias, para depois, no final da feira, desmontar tudo, o que resulta em um trabalho diário, repetitivo e enfadonho. 
Haesbaert (2007, p.7) esclarece que a territorialidade torna-se algo mais amplo do que território, de modo que "a todo território corresponde uma territorialidade, mas nem toda territorialidade implica na existência de um território". Assim, enquanto o território pressupõe uma base material, concreta, a territorialidade implica em um "[...] referencial territorial (simbólico) para a construção de um território, que não obrigatoriamente existe de forma concreta".

O cotidiano da feira, nesse sentido, também é marcado pelo movimento dos vendedores ambulantes no calçadão que revela uma territorialidade conflituosa entre estes e os feirantes. Dentre outros fatores, isso se dá pelo fato de o feirante ter que recolher taxas à municipalidade em função da ocupação do espaço público, diferentemente do vendedor ambulante que está "livre" dessa obrigação. Nesse embate, manifesta-se a dimensão do território com a demarcação de fronteiras nem sempre visíveis a olho nu, mas percebida no movimento dos corpos, dos olhares e acordos forjados no espaço vivido para uma convivência menos irascível.

Por outro lado, os vendedores ambulantes, inseridos na área do calçadão, no entorno da feira, estabelecem territorialidades mediante uma mobilidade compulsória. Para permanecerem naquele espaço, muitos ambulantes utilizam o próprio corpo como marco de sua territorialização para vender seus produtos diante da impossibilidade de fixação e imposição de sua mobilidade pelo poder público.

A condição de instabilidade constante e da imposição do movimento, todavia, fez com que estes trabalhadores, ante a necessidade de sobrevivência, buscassem traçar estratégias espaciais no sentido de resistir à norma urbana e permanecer trabalhando no calçadão.

Haesbaert (2006, p.236-237), nesse sentido, defende uma concepção mais dinâmica de território em que se pode falar em uma territorialização no movimento, reconhecendo que a “[...] territorialização pode ser construída no movimento, um movimento sobre o qual exercemos nosso controle e/ou com o qual nos identificamos". Entende-se que esses trabalhadores, feirantes e vendedores ambulantes, se territorializam pelo movimento, tanto pelo movimento de montagem e desmontagem das barracas da feira quanto pelo movimento dos ambulantes no calçadão, lado a lado de uma fiscalização que não lhes permite parar.

A mobilidade aqui adquire relevância maior do que no passado para esses trabalhadores e passa a ser uma característica particular para o calçadão em que tudo é 
suscetível ao movimento. Jacques Lévy (2001, p.1) define mobilidade “[...] como a relação social ligada à mudança de lugar, isto é, como o conjunto de modalidades pelas quais os membros de uma sociedade tratam da possibilidade de eles próprios ou outros ocuparem sucessivamente vários lugares”. Aqui mobilidade não está restrita ao mero deslocamento, mas sim como relação social que envolve o capital social disponível, sem esquecermos as determinações postas ao indivíduo no espaço urbano. A mobilidade está ligada, assim, às possibilidades e à competência de mobilidade que o indivíduo desenvolve no espaço urbano.

Desse modo, para o vendedor ambulante, ora a mobilidade é uma condição positiva, tendo em vista conseguir alcançar outros públicos e, assim, auferir maior renda, ora é uma imposição e condição sine qua non para se manter no calçadão, tornando-se, com efeito, uma condição negativa, haja vista que a fiscalização não permite o ambulante se manter parado em determinado ponto.

Para os feirantes o vendedor ambulante pode ser considerado um "invasor", que ameaça o seu território, suas vendas. Já o turista, ou seja, o "estrangeiro", é bem recebido em função do interesse do feirante em comercializar seus produtos. Mesmo diante de turistas de outros países, as barreiras do uso da língua são quebradas por outros recursos, como o uso de um aparelho celular para informar o preço da mercadoria.

As formas de tratamento, desse modo, ressaltam essa receptividade, tão propalada como traço característico do cearense: "Boa noite, cliente, posso ajudar?" ou "Pois não, moça, fique à vontade", situação esta que corrobora a asserção de Márcio Piñon de Oliveira $(2007$, p.175) de que o cidadão é “"[... aquele que pode participar como consumidor e usuário da cidade; o que não pode [encontra-se] cada vez mais, à margem dela".

Pode-se afirmar, ainda, que o vendedor ambulante é o "vagabundo", na acepção metafórica de Zygmunt Bauman ${ }^{2}$, que, assim como tantos outros trabalhadores da Beira-Mar, foram sujeitados historicamente a prestar serviços aos "turistas". Desse modo, “[...] se estão em movimento é porque foram impelidos por trás" (BAUMAN, 1998, p. 117). Sua liberdade difere da liberdade do turista, sendo um misto de

\footnotetext{
2 As figuras do turista e do vagabundo aqui enfocadas remetem à metáfora de Bauman (1998, p. 118). Para esse autor "[...] uma pessoa pode ser (e frequentemente o é) um turista ou um vagabundo sem jamais viajar fisicamente para longe".
} 
consciência dos limites da atividade ambulante no calçadão e de ruptura da estrutura imposta pelo Poder Público.

A feira da Beira-Mar, como um espaço de representação da cultura cearense pelo comércio de artesanato, revela-se um lugar heterogêneo, quer pela organização da atividade comercial do artesanato, quer pela arregimentação de trabalhadores, reunindo uma diversidade de sujeitos, que, de variadas formas, transformam aquela porção do calçadão não apenas num ponto de venda de mercadorias, mas num território constituído de várias dimensões - políticas, econômicas e culturais.

\section{Organização do trabalho no interior da feira e a formação de subcircuitos do trabalho informal}

Interessante destacar como se estabelecem duas temporalidades distintas em relação ao uso do calçadão na avenida Beira-Mar. Uma marcada pelo uso diurno, relacionado com as práticas de esportes, caminhadas etc.; e a outra, no período da tarde e da noite, quando essa funcionalidade muda, ou seja, instala-se outra dinâmica conduzida pela feira no movimento de carrinhos e feirantes que chegam para montar suas barracas e no maior movimento de turistas, sem, contudo, excluir a marcha dos praticantes de caminhadas no calçadão.

A feira é constituída pela área no calçadão entre a avenida Desembargador Moreira e a rua Osvaldo Cruz. É aí onde se encerra o local de trabalho do feirante, com a marcação da área para a montagem das barracas. Entre os feirantes que produzem e/ou vendem na feira, detectam-se diferentes níveis de organização, desde a técnica artesanal empregada, o capital disponível, até a arregimentação da mão de obra na fabricação e comercialização dos produtos. A produção das mercadorias vendidas na feira é, em geral, realizada em bairros da periferia de Fortaleza, não obstante, também, a ocorrência de mercadorias vindas de vários municípios cearenses e outros estados nordestinos.

Na feira, pode-se, ainda, verificar um pouco do que Santos (2008, p. 199) acentua ao descrever o circuito inferior da economia urbana, ou seja, "[...] o jornal usado torna-se embalagem, o pedaço de madeira se transforma em cadeira, as latas, em reservatórios de água ou em vasos de flores [...]”. Na feira, o jornal também é usado para embalar os produtos, mas, igualmente, se torna matéria-prima para a fabricação de arranjos, molduras etc.; as latinhas de cerveja são reaproveitadas, ganham aselhas e tornam-se canecas. As garrafas PET transformam-se em brinquedos. Materiais como as 
sucatas, nas mãos dos artesãos, ganham formas estatuárias; as sobras de couro da fabricação de sandálias tornam-se miniaturas das próprias sandálias ou pequenos chapéus de cangaceiros em chaveiros, isso para citar alguns materiais reaproveitados.

A feira, no que concerne à sua constituição, compõe-se, basicamente, de três equipamentos fundamentais, que lhe asseguram as condições materiais de funcionamento. São eles: a barraca, o carrinho e a bateria (Figura 1). Segundo depoimentos de feirantes mais antigos, nos primeiros anos do comércio de artesanato na Beira-Mar, "[...] todos traziam a sua barraca e as suas mercadorias na mão", organizando-as na calçada.

Essa situação evoluiu à medida que foram sendo utilizadas barracas desmontáveis e carrinhos $^{3}$ para guardar e transportar as mercadorias. A barraca é formada por uma estrutura metálica composta por tubos de ferro, encaixados uns nos outros, formando uma área de 2x2 metros. Além da estrutura metálica, outros instrumentos compõem a barraca, como bancadas de compensado, ganchos de ferro, caixas e cabides que servem para expor as mercadorias, as quais ficam suspensas na barraca, além de outros acessórios menores. As barracas são distribuídas em fileiras no calçadão e funcionam no período das $16 \mathrm{~h}$ às $23 \mathrm{~h}$, implicando uma rotina diária de montagem e desmontagem.

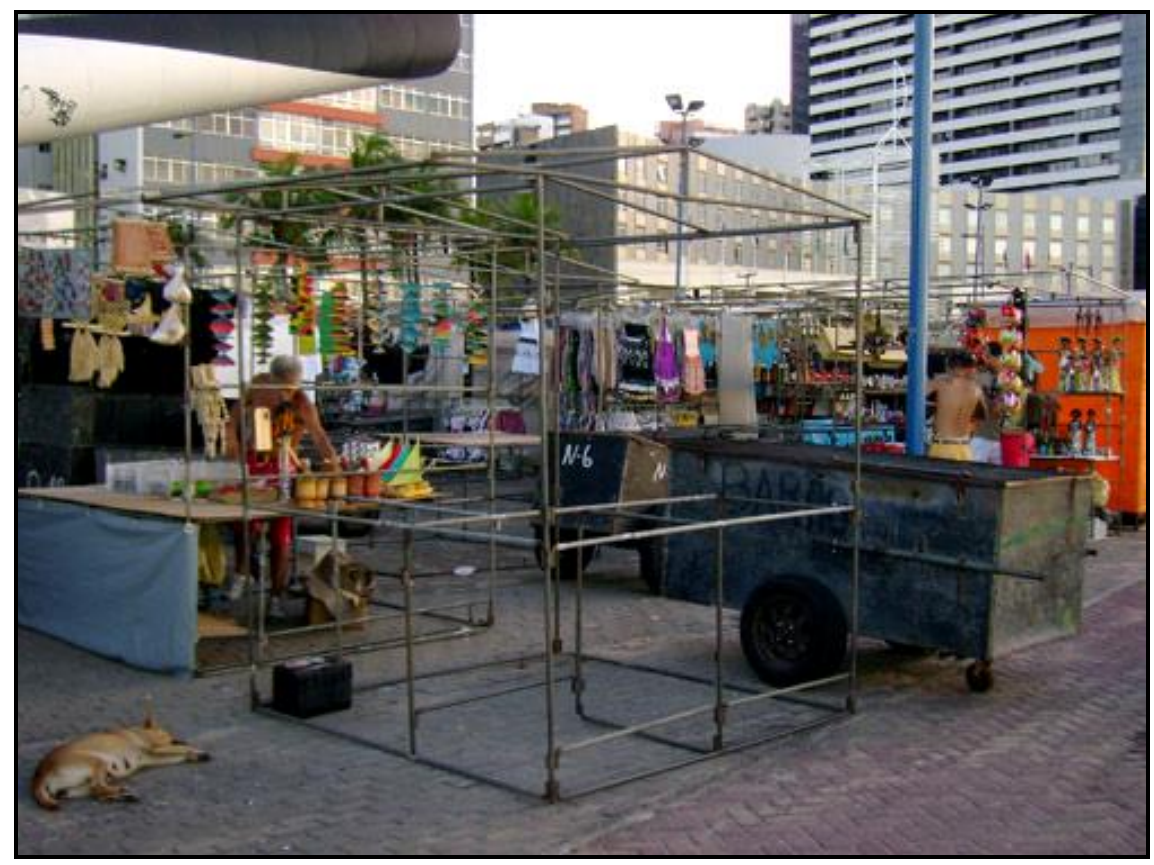

FIGURA 1 - A barraca, o carrinho e a bateria. Fonte: GONÇALVES, 2008.

\footnotetext{
${ }^{3} \mathrm{O}$ carrinho é uma espécie de baú feito de chapas de ferro soldadas e fixado sobre um eixo com rodas de automóvel.
} 
O trabalho de montagem e desmontagem das barracas é feito por trabalhadores denominados montadores que, em geral, também atuam como carregadores dos carrinhos de mercadorias no deslocamento do depósito até a feira ${ }^{4}$. Eles desenvolvem, assim, uma atividade que está diretamente relacionada à constituição e organização da feira, não obstante a presença de outros segmentos de trabalhadores, como os vendedores das barracas e, ainda, os carregadores de bateria, que prestam o serviço de iluminação das barracas, assunto este que será abordado mais adiante. Essas atividades de suporte que estamos denominando de subcircuitos do trabalho precário, subsidiam a organização e funcionamento da feira.

Por volta das $13 \mathrm{~h}$, com sol a pino, já se observa o movimento dos carregadores no calçadão. A presença desses sujeitos é marcada pelo esforço físico mediante tração humana no transporte dos carros de mercadorias para o local da feira. Corpos esguios, nem sempre bem alimentados, queimados do sol, envolvidos no movimento de ir e vir. Após levar um carrinho para o calçadão, o carregador retorna ao depósito para pegar outro, repetindo esse percurso diversas vezes.

Às $15 \mathrm{~h}$, a movimentação torna-se mais intensa. A feira vai ganhando forma e extensão com a montagem das mais de 600 barracas. Nesse momento, a ação dos carregadores é fundamental (Figura 2) no transporte e posicionamento dos carrinhos de mercadorias nos pontos onde será montada a respectiva barraca. Enquanto isso, os montadores vão lhe dando forma. Em muitas ocasiões, o próprio carregador é o responsável pela montagem da barraca, cabendo aos feirantes apenas organizar as mercadorias.

A maioria dos permissionários da feira guarda o carrinho de mercadorias no depósito, também denominado por eles como o "estacionamento dos carrinhos". Eles pagam um aluguel que custa, em média, $\mathrm{R} \$ 26,00$ por semana (valores de 2008), porém esses valores variam de acordo com o tamanho e peso dos carrinhos, uma vez que, quanto maior o carrinho, maiores são o aluguel do depósito e o valor cobrado pelo carregador para transportá-lo.

\footnotetext{
4 Os carrinhos com as mercadorias são guardados em um depósito na rua Visconde de Mauá, perpendicular à avenida Beira-Mar. Esse local assim funciona desde os anos 1980, quando ainda havia muitos terrenos desocupados. Acredita-se que a permanência desse terreno em uma área de grande valorização imobiliária, como é a Beira-Mar, decorre, em parte, da renda auferida com o aluguel da área para depósito dos carrinhos da feira.
} 


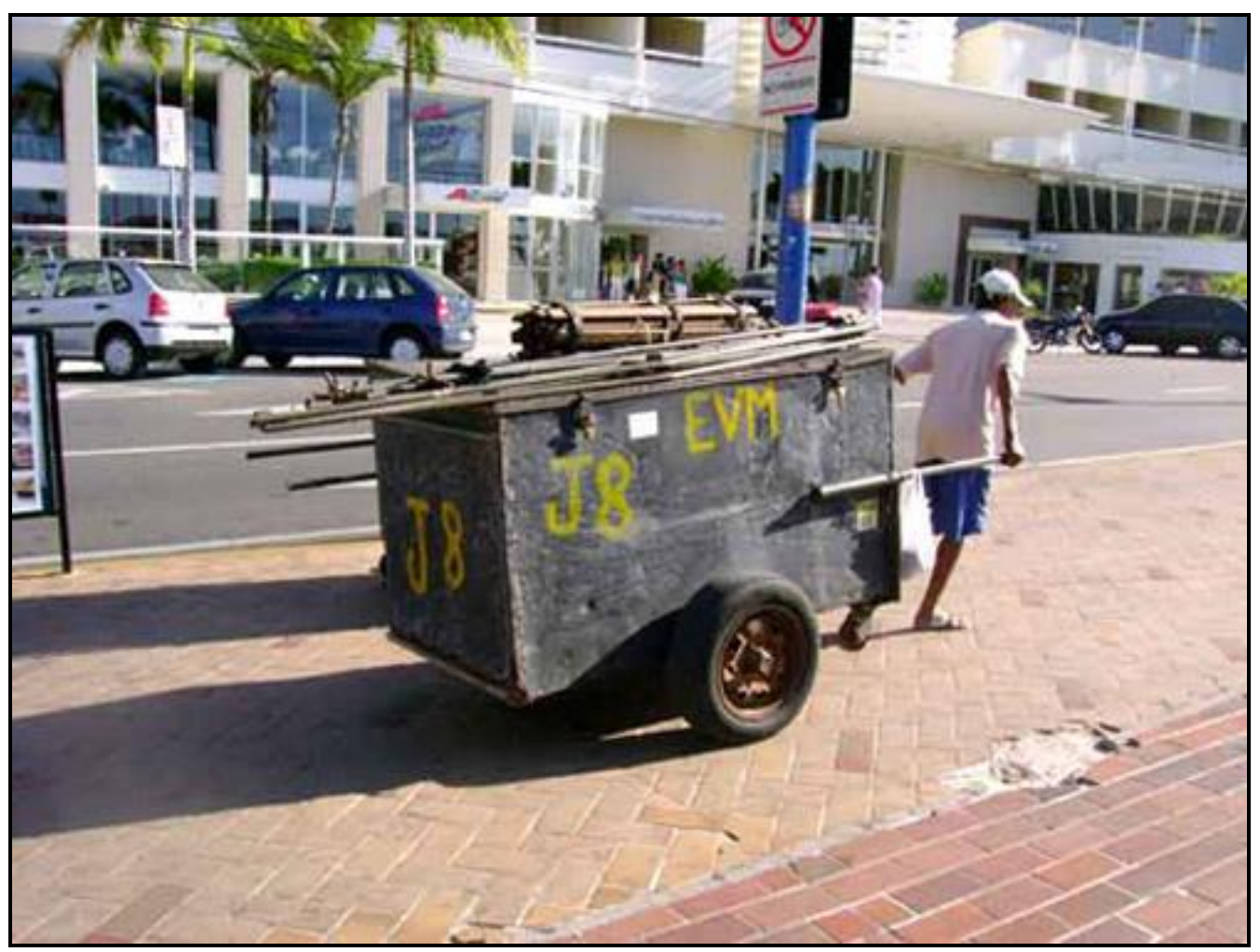

FIGURA 2 - O carregador do carrinho. Fonte: GONÇALVES, 2008.

Cada feirante é responsável pela contratação do seu carregador/montador, sendo alguns pagos apenas para montar e desmontar as barracas, enquanto outros são contratados somente para conduzir o carrinho até o local onde será montada a barraca. Um carregador, em geral, ocupa-se do transporte do carrinho e da montagem/desmontagem de, aproximadamente, 20 barracas, chegando a atender até 30 feirantes por dia. Todavia, quando assumem um número maior de barracas, ocorre uma sobrecarga de trabalho, o que os leva a contratar um auxiliar, que é denominado por eles como o "carregador do carregador", constituindo-se, assim, outro grupo de sujeitos inseridos no subcircuito de trabalho da feira e, portanto, no trabalho precário.

Com o avançar da noite, a feira vai sendo desmontada aos poucos. Por volta das $22 \mathrm{~h}$, algumas barracas começam a ser desarmadas pelos feirantes muito em função do tempo e retorno seguro para casa. Ao final da feira, a mesma dinâmica se repete, só que essa etapa está mais subordinada à ação dos carregadores que entram noite adentro na tarefa de desmontagem das barracas e retorno dos carrinhos para o depósito ${ }^{5}$.

\footnotetext{
${ }^{5}$ Há ainda aqueles feirantes que não utilizam o serviço do carrinho, transportando e guardando suas mercadorias em veículos próprios que estacionam na avenida. Esses, todavia, não constituem a maioria, sendo o serviço do carrinho o mais utilizado.
} 
O pagamento dos carregadores é efetuado, em geral, semanalmente, e os valores variam de $\mathrm{R} \$ 11,00$ a R \$ 75,00 (preços de 2008), também de acordo com o tamanho dos carrinhos. Para os montadores de barraca (Figura 3) esse valor é pago diariamente como o custo para montar a barraca, que é de dois reais por dia, ou, como afirma um feirante: “[...] é um real para armar e outro para desarmar", e ainda mais um real para o carregador estacionar o carrinho na praia ${ }^{6}$.

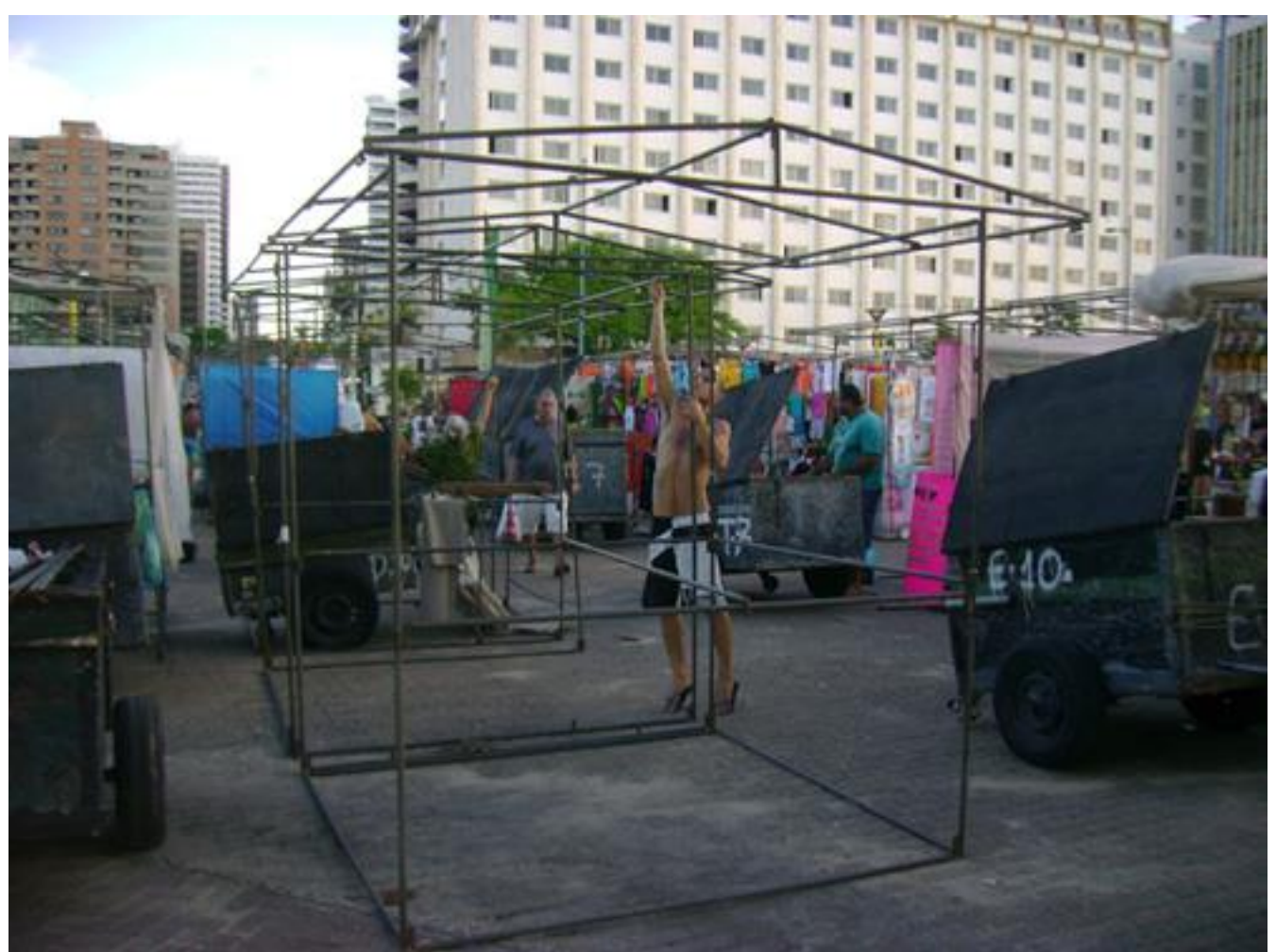

FIGURA 3 - O montador da barraca. Fonte: GONÇALVES, 2008.

Essas são formas árduas de trabalho que consomem grande energia e provocam desgaste físico pela ação da tração humana na condução dos carrinhos, empurrados em um percurso de 200 metros do depósito até a feira. Uma condição informal de trabalho que permite a sobrevivência de muitos trabalhadores na Beira-Mar.

Em seu estudo sobre os trabalhadores do barro (oleiros e louceiros) no sul do estado de Sergipe, Beatriz Góis Dantas (1987) atribui à denominação de "trabalho pesado" a ação dos grupos domésticos de produção, a qual exige maior força física,

\footnotetext{
${ }^{6}$ Em função de portaria (03/2006) expedida pela Secretaria Executiva Regional II - SER II/PMF, visando a disciplinar a utilização dos carrinhos e ordenar o transporte destes pelo calçadão, foi proibido o trânsito dos carrinhos fora do horário de montagem das barracas (das $15 \mathrm{~h}$ às $16 \mathrm{~h} 30 \mathrm{~min}$ ) e de desmontagem (das $23 \mathrm{~h} 30 \mathrm{mim}$ à $1 \mathrm{~h}$ ), de forma que muitos feirantes utilizam a faixa de praia, contígua ao calçadão, para deixar os carrinhos durante o horário da feira.
} 
como rachar a lenha para a queima da louça. Essa ação é atribuída aos homens da comunidade, haja vista que exige maior força física. No caso da feira da Beira-Mar, dado o grande esforço demandado para o transporte, montagem/desmontagem das barracas e o grande número de feirantes mulheres, muitas das quais senhoras de idade avançada, ocorre o repasse desse trabalho pesado para outros indivíduos pagos para executar a tarefa diária que envolve a montagem da feira como um todo.

A iluminação é outro componente necessário ao funcionamento da feira, haja vista a iluminação pública ser insuficiente para propiciar a exposição das mercadorias nas barracas. A iluminação à bateria constitui um recurso que supre essa deficiência, sobretudo, nas barracas instaladas em locais mais distantes dos postes de iluminação pública, gerando, com isso, mais um custo adicional aos feirantes. Trata-se de um sistema de aluguel de baterias ofertado às barracas (Figura 4), de modo que outro grupo de trabalhadores é "contratado" para a função de transportar e instalar as baterias nas barracas. Diferentemente da função do carregador da barraca, que exige maior força física na tração humana dos carrinhos, o manuseio da bateria exige algum conhecimento para sua condução e instalação na barraca, requerendo, ainda, a utilização mínima de instrumentos de proteção, como as luvas, por exemplo.

Segundo dados fornecidos pelos feirantes, em dezembro de 2008, o serviço de aluguel e transporte da bateria custava algo em torno de $\mathrm{R} \$ 40,00$ (mensais) ou $\mathrm{R} \$$ 10,00 (semanais) ${ }^{7}$, acordo esse que também varia conforme o capital disponível e/ou o volume de vendas do feirante. Todavia, isso não exclui a busca do feirante para diminuir os custos de manutenção da barraca. Muitos permissionários acabam providenciando a instalação elétrica e a aquisição de uma bateria própria, tendo em vista que esta constitui mais uma despesa que eleva o custo fixo mensal de sua atividade, o que pode ser constatado no depoimento de um feirante: "Eu tinha bateria, mas entreguei porque era mais uma despesa".

\footnotetext{
${ }^{7}$ Para alguns feirantes esse custo é maior em virtude do consumo da bateria em função do maior número de lâmpadas utilizadas. Em algumas barracas, utilizam-se até três pontos de luz para melhor exposição da mercadoria.
} 


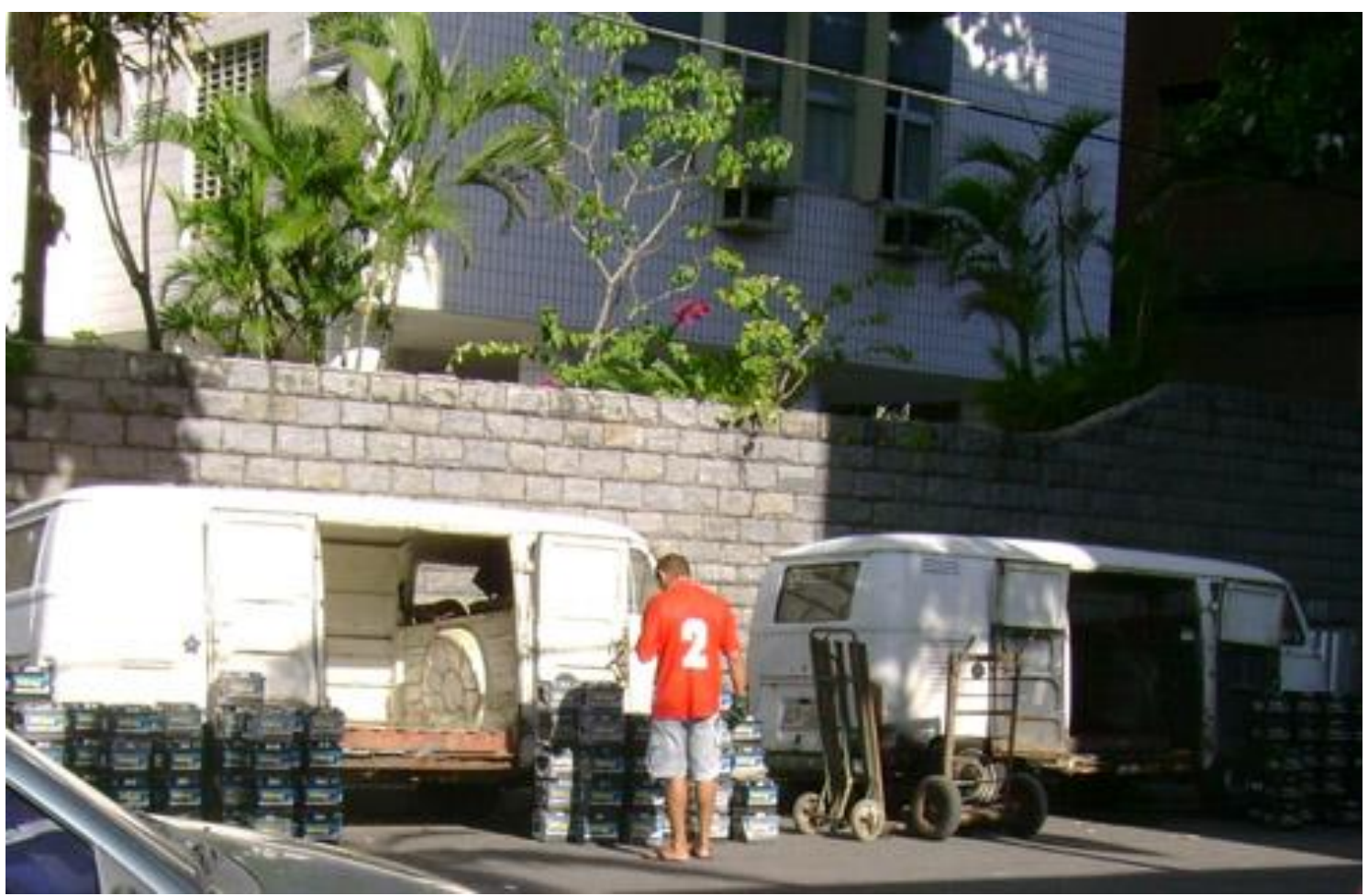

FIGURA 4 - Veículos que fazem o transporte das baterias até a feira. Fonte: GONÇALVES, 2008.

O uso da bateria nas barracas é bastante disseminado entre os feirantes, com exceção daqueles que têm suas barracas próximas aos postes de iluminação pública ou, ainda, investem parte do seu lucro na aquisição de uma bateria própria, conforme o relato de outro feirante: "Comprei eu mesmo uma bateria, aí contrato só o carregador".

No interior da feira, atua, ainda, outro grupo de trabalhadores, que formam o subcircuito da alimentação, constituído pelos vendedores ambulantes de lanches, refeições em marmitas, comidas típicas, água mineral, café, chá, refrigerantes, dentre outros produtos que complementam a alimentação dos vendedores e permissionários durante o tempo de trabalho na feira. Esses vendedores têm livre circulação na área da feira, diferentemente dos outros, tendo em vista que sua mercadoria não concorre com os produtos dos feirantes.

Uma parte das barracas conta, ainda, com vendedores que trabalham auxiliando o permissionário nas vendas e atendimento de clientes. Estes, em geral, também trabalham informalmente, e seus ganhos são irregulares, variando de acordo com o que foi combinado com o permissionário.

Para os feirantes os gastos são semanais. Neles se incluem carregador, montador, vendedor, fornecedores, além da alimentação, já que o trabalho na feira requer uma permanência de longas horas. Os gastos com o transporte, montagem/desmontagem e o 
aluguel do depósito do carrinho podem chegar a um custo fixo de manutenção da atividade de quase $\mathrm{R} \$ 300,00$ por mês (valores de 2008). Por essa razão, torna-se, pois, evidente o esforço do feirante em reduzir os custos de manutenção da sua atividade no calçadão. Entretanto poucos fogem ao esquema que, atualmente, constitui a feira, ou seja, a necessidade do pagamento dos serviços de transporte do carrinho, de montagem/desmontagem da barraca e do aluguel da bateria.

\section{Considerações finais}

Conforme já destacado em trabalhos anteriores, no calçadão da orla "[...] tudo é flexível, é desmontável, passível de mobilidade" (GONÇALVES; AMORA, 2009, p. 107). Assim, o uso do calçadão também é mediado por uma dimensão espacial onde montar, desmontar e carregar constitui uma condição relacional que não está restrita apenas aos carregadores e montadores, mas se estende a outros sujeitos que atuam naquele espaço litorâneo.

A organização e o funcionamento da feira mobilizam um grande contingente de trabalhadores e trabalhadoras, envolvendo várias etapas e momentos, desde a montagem/desmontagem, transporte das mercadorias, serviço de iluminação e comercialização, revelando, por um lado, uma parcela considerável de pessoas inseridas nessas atividades e, por outro, a forma precária dessa inserção.

Essa prática generalizada na feira utiliza, literalmente, a força de trabalho de mulheres e homens que formam subcircuitos do trabalho precário, atuando no interior da feira em atividades parciais, com ganhos irregulares, levando a uma sucessiva exploração do trabalho, uma vez que se torna uma alternativa para trabalhadores desempregados e/ou excluídos do mercado formal, os quais, movidos pela necessidade de sobrevivência, se inserem no trabalho da feira, passando, ali, a ganhar o seu sustento.

A feira constituiu um território institucionalizado pelo Poder Público, não obstante também ser submetida a uma mobilidade compulsória diária (montagem/desmontagem), além das lutas empreendidas pelos feirantes, no sentido de uma constante reafirmação desse território pela presença desses sujeitos no calçadão, subordinados às várias ações normatizadoras. Já os ambulantes, movidos pela necessidade da sobrevivência, conformam territorialidades, além de serem impelidos ao movimento. Assim, enquanto o território para o feirante se forma concretamente na montagem e desmontagem das barracas, para o vendedor ambulante, essa apropriação é 
marcada por territorialidades que, embora não existam de forma concreta, constituem uma estratégia espacial que perpassa a elaboração de um referencial de territorialização no calçadão.

Finalizando, ressalta-se que o cotidiano do trabalho na feira de artesanato da avenida Beira-Mar perpassa pela rotina diária de montar, desmontar e carregar. De outro modo, essa condição permite que a feira se refaça todos os dias na vida daqueles que a constroem mediante o contato com outras pessoas, costumes e sotaques, relações que fogem ao cotidiano do trabalho na feira da Beira-Mar.

\section{Referências bibliográficas}

BAUMAN, Zygmunt. 1998. O mal-estar da pós-modernidade. Trad. Mauro Gama; Cláudia Martinelli Gama. Rio de Janeiro: Jorge Zahar Editor.

DANTAS, Beatriz Góis. 1987. A mão e o torno: a divisão sexual do trabalho entre os produtores de cerâmica. Revista Geonordeste, Aracaju, ano 4, n. 1, p. 17-29.

GONÇALVES, Luiz Antonio Araújo; AMORA, Zenilde Baima. 2009. O lazer e a Beira-Mar de Fortaleza: temporalidades e territorialidades. In: AMORA, Zenilde Baima (Org.) Cenários geográficos: reflexões e enfoques. Fortaleza: EdUECE.

HAESBAERT, Rogério. 2006. O mito da desterritorialização: do "fim dos territórios" à multiterritorialidade. 2 ed. Rio de Janeiro: Bertrand Brasil.

2007. Identidades territoriais: da multiterritorialidade à "reclusão" territorial. Conferência. In: 23 GeoForum. Disponível em: <http://tercud.ulusofona.pt/ GeoForum/Ficheiros/23GeoForum.pdf>. Acesso em: 08 jun. 2008.

LÉVY, Jacques. 2001. Os novos espaços da mobilidade. GEOgraphia. Niterói/RJ, n. 6, p 1-11. Disponível em: <http://www.uff.br/geographia/rev_06/levy6.pdf.>. Acesso em 31 out. 2007.

OLIVEIRA, Márcio Piñon de. 2007. O retorno à cidade e novos territórios de restrição à cidadania. In: SANTOS, Milton et al. Território, territórios: ensaios sobre o ordenamento territorial. 3. ed. Rio de Janeiro: Lamparina.

SANTOS, Milton. 2008. O espaço dividido: os dois circuitos da economia urbana dos países subdesenvolvidos. Trad. Myrna T. Rego Viana. 2. ed. São Paulo: EdUSP. 
Para citar essa obra:

GONÇALVEZ, L. A. A. Pra tá aqui tem que montar, desmontar e carregar": Mobilidade, território e cotidiano do trabalho na feira de artesanato da Avenida Beiramar, Fortaleza (CE). In: RUA [online]. 2014, no. 20. Volume 1 - ISSN 1413-2109. Consultada no Portal Labeurb - Revista do Laboratório de Estudos Urbanos do Núcleo de Desenvolvimento da Criatividade http://www.labeurb.unicamp.br/rua/

Capa: FORTALEZA MAGAZINE. s./d. Beira mar. Disponível em: http://www.fortalezamagazine.com/beira-mar-fortaleza.html

Laboratório de Estudos Urbanos - LABEURB

Núcleo de Desenvolvimento da Criatividade - NUDECRI

Universidade Estadual de Campinas - UNICAMP

http://www.labeurb.unicamp.br/

Endereço:

LABEURB - LABORATÓRIO DE ESTUDOS URBANOS

UNICAMP/COCEN / NUDECRI

CAIXA POSTAL 6166

Campinas/SP - Brasil

CEP 13083-892

Fone/ Fax: (19) 3521-7900

Contato: http://www.labeurb.unicamp.br/contato 